\title{
Response to Stephen D. Brookfield's Why White Instructors Should Explore Their White Racial Identity
}

Shantih E. Clemans, SUNY Empire State College

In principle, I agree with Stephen Brookfield's strong assertion that white teachers need to carefully explore what it means to be white. However, I have two primary points of departure. First, Brookfield falls short in offering practical guidance to support the imperative of whiteexploration. While I see the importance of white people embarking on self-exploration, I have more practical concerns. Specifically, how, when and why explorations connected to racial identity occur are the more pressing considerations for the flame of change to ignite in the hearts, minds and practices of teachers (and in all of us, frankly).

Second, Brookfield claims that we need to reject a "color blind view of the world for its seeming emphasis on the universal aspect of humanity." He also suggests that whiteness can be separated out from other aspects of human identity. On the contrary, I see the more chances we take to learn from each other - teacher, student, black, brown, white (and all) - the more seeds of empathy are planted, the more commonalities we recognize in each other. Rather than something to critique, humanness is actually a doorway in, a tool to unlock the gnarly puzzle of privilege and power. In college-readiness programs and community-based GED centers, one small way white-dominated conceptualizations of humanness can be redirected is through the creation of learning activities that are rooted in personal experiences connected to race, such as pair interviewing exercises, reflective journals, and autobiographies (Clemans, 2017). "Many teachers include activities that engage students in sharing their experiences and finding their commonalities - not just personal characteristics such as how many sisters they have, but talking about how an issue touches their daily lives" (Nash, 2019, p. 64). I maintain that only through curiosity, genuine care, openness, and listening to people's life experiences (really listening from their perspective) can whiteness (and blackness, femaleness, and queerness for that matter) be brought into sharp focus.

\section{Practice Considerations}

Brookfield's claims are fast and furious. Maybe too fast. Personal exploration on whiteness is a complex undertaking with delicate practice considerations, specifically: context, timing, audience, visibility, and purpose.

Let's begin with context. Under what conditions and circumstances are these explorations in white racial identity occurring? Is the setting a public 
library with a summer class for new immigrants learning English? Is the teacher preparing to facilitate a discussion on race and power in America? Or is it a pre-college math class? I'd argue that it matters.

Next is the important consideration of timing. When are or when should explorations about one's whiteness happen? For example, does a white teacher jump right in on day one of the workshop series and say, "I'm white and this is what it means." Or, do the results of this exploration happen after the students and teacher have established a routine, where certain expectations for learning, even a fledging trust, have developed? If we are considering whiteness in an ongoing workshop, self-awareness around racial identity needs to be a theme woven throughout the weeks of the training.

What about the audience? For example, what are the reflections on whiteness teachers have with themselves? Meaningful mechanisms are necessary to guide and support internal reflections about one's racial identity and the power connected to one's identity. External audience also needs consideration. For example, after some version of internal reflection and self-examination, what are the next steps?

What are the aspects of self-awareness a teacher keeps private and what is shared with colleagues as a way to learn together? Adult educators of all backgrounds need opportunities to talk about race in a nonjudgmental space. Are there people or groups who should be excluded from these reflective explorations? What are the learning moments connected to whiteness that a white teacher decides to have with white and of-color co-workers, with students, community members, or other program stakeholders? Are there "safe spaces" where teachers can honestly share what is on their minds and in their hearts connected to race without fear of judgment?

Finally, perhaps the biggest question: purpose. What is the ultimate point of self-exploration connected to white racial identity? Does such learning improve students' literacy? What are specific examples of self-exploration for white teachers? Beyond theoretical, what would a dayto-day reflection around race look like in practice for an $\mathrm{ABE}$ instructor? For example, is it a journal project? Is it a book discussion group?

\section{Humanness}

I have thought deeply about my whiteness, sometimes as a separate part of me and, more often, as one piece of me that makes up my human tapestry. I enter this conversation as a white woman, a lesbian, a feminist, a social worker, partner, parent, faculty mentor, community educator, and a director of a center focused on mentoring, teaching, and learning. My first eyeopening awareness of white privilege, how I smoothly navigate my world, came after reading Peggy McIntosh's "Unpacking the Invisible Knapsack." Which, to my mind, is the original and most powerful work to date on the subject of whiteness. (Brookfield would have done well to acknowledge McIntosh's seminal work.) In her "Some Notes for Facilitators," McIntosh (2010) encourages educators to take a broad view: "Recognize that all people are both located in systems and also uniquely individual” (p. 5).

My most profound learning around racial identity continues to unfold, expand, surprise, and challenge me through my teaching and mentoring adult students. Adult learners are a vast population-college-bound, college-enrolled, in GED programs, with many hopes and aspirations for skill development and lifelong learning. 
Moreover, I have also worked with communitybased organizations to facilitate workshops connected to race and culture for a broad range of participants, including correction officers, childcare workers, and substance abuse counselors in training. In these settings, I have often been one of a few white people in the room. I have wondered if I may have a little glimpse of what African American and black learners feel every day. I now realize I cannot make any such claim. No matter if I am "the only" one, I still have the freedom, as Brookfield observes, to "opt in and out of race."

Although I was keenly aware of my own whiteness in such teaching encounters, I lacked the language or confidence to openly acknowledge my white privilege. Over time, my relationships with my students and my commitment to authentic teaching deepened, and I slowly recognized mistakes that come from honestly embarking on "tough" human conversations.

\section{Focus on the Individual}

I question Brookfield's claim that "in tribal, indigenous and Afrocentric culture it is the collective that validates knowledge and take responsibility for moving knowledge forward." These sweeping generalizations about vast populations of people across the world do nothing to add depth or nuance to cultural experiences in learning. I challenge Brookfield's assertion that individual rather than group assessment reinforces white supremacy. In our racist American culture, are not group assessment processes influenced by the same systems of white supremacy as other educational systems? Doesn't Brookfield's claim that, "because of the white supremacy embedded in the way they function, the dignity of individual members of color can only be enacted if there are radical structure changes in admissions, financial aid, assessment systems, governance, curricula and performance appraisal" negate current collective strategies for assessment? How overwhelming! We need to embrace small steps to honor the dignity of our students and teachers of color.

\section{On Trust}

Brookfield also asserts that trust is not something we can assume in our relationships with colleagues of color. I would argue not for instant (superficial) trust, but rather for the acknowledgement of a certain process connected to teachers learning self-awareness around whiteness, as a precursor to trust. I firmly believe that trust develops through a teacher taking an interest in students' lives: learning about passions, dreams, joyous and painful life experiences, a desire to learn to read and write English. Although individual attention to students is essential, groups, specifically in-person classes, are especially powerful modalities to learn together about racial identities and other parts of what makes us human.

To understand and attend to whiteness as connected more broadly to teachers' identity, is an ongoing commitment for me. In my 2017 essay, "On Love and Learning: Reflections of a White Professor 'Teaching' Black Adult Students," I wrote on my experiences and reflections during a semester of teaching Cultural Competency to a group of mostly black and African American adult college students. My essay was about my internal process, which was bumpy, beautiful and powerful. The heart of the essay was my teaching journal entries combined with my students' journal entries. Here's what I wrote in the conclusion:

Talking across difference can be fraught with danger. There is no returning to the blind comfort, the reassurance that everything will be $\mathrm{OK}$, or the notion that "I am white but I am not like those 
other white people." A subject as complex as culture, as divisive as race and racism, is not a cursory exercise, not a semesterlong undertaking earning one a badge of "competent." For both student and teacher, cultural competency begins as a long, slow and conscious process of understanding oneself and then another person from that person's viewpoint, perspective, history and circumstance (p. 21).

I urge us as teachers to begin with an openhearted commitment to humanness. Do white educators learn, really learn, about the lives, experiences, hopes and challenges of their students of color?

\section{Fear and Defensiveness}

Honest conversations about whiteness, privilege, discrimination and race are painful, fraught, and crucial. There is a chance that once a white person feels defensive and challenged in discussions about power, race and privilege, this person may be less likely to venture into future conversations out of fear of making a mistake or saying something wrong or feeling attacked or vulnerable.

One reading I have used in various settings is Peggy McIntosh's "Unpacking the Invisible Knapsack." To be honest, probably out of a combination of fear and defensiveness, I have worried about the usefulness of this reading. I have convinced myself that black and African American learners do not actually need a lesson on white privilege. With more thought, I realized I was protecting myself from facilitating a difficult conversation where my feet would feel unstable under me. I also realized I didn't want to go there, to have my whiteness so exposed to my students. I don't think my experiences are unusual. Uncertainty, fear, flushed face and cracking voice were all necessary for me to speak honestly about myself, my privilege, and to listen and learn from my students.

Still, something nags at me about the entire process of exploring one's whiteness. I see a tension between white self-exploration on race with the purpose to strengthen teaching and white exploration on race as yet another manifestation of unchecked white domination. In other words, when does a white person's explorations on whiteness actually contribute to, rather than shine light on the very systematic supremacy we are trying to eliminate? It is dangerous when explorations on whiteness, to return to Brookfield, "help maintain a system that exhibits structural exclusion and normalizes brutality."

\section{Teacher Development}

Brookfield makes a case that the real work happens internally for white teachers when they take time, store up a certain kind of courage, take stock of themselves before embarking on sharing with students. Schools and communitybased organizations are well situated to create a menu of workshop activities and offerings connected to privilege, power and identity. With skilled facilitators in place, these workshops need to be flexible and relevant to particular teachers and students, for example a session on cultural reflection for $\mathrm{ABE}$ teachers would be a welcome addition. Educators benefit from ongoing professional development opportunities, both mandatory and optional, that support, challenge, and strengthen mutual learning about our lives. Our diverse adult learners deserve our care and attentiveness to ourselves and them. 


\section{References}

Clemans, S.E. (2018). On love and learning: Reflections of a white professor "teaching" black adult students. Dialogues in Social Justice: An Adult Education Journal, 3(1). Retrieved from https://journals.uncc.edu/ dsj/article/view/701/719

McIntosh, P. (2010). Some notes for facilitators. Wellesley Centers for Women, National SEED Project on Inclusive Curriculum.
McIntosh, P. (1989). White privilege: Unpacking the invisible knapsack. Wellesley Centers for Women, National SEED Project on Inclusive Curriculum.

Nash, A. (2019). Showing up for immigrant learners (and each other). Adult Literacy Education: The International Journal of Literacy, Language and Numeracy, 1(1), 63-66. 